\title{
Cancer Bioinformatics Infrastructure Objects
}

National Cancer Institute

\section{Source}

National Cancer Institute. Cancer Bioinformatics Infrastructure Objects. NCI Thesaurus. Code $C 42878$.

The vision for caCORE is to provide a common data management framework that will support the consistency, clarity, and comparability of biomedical research data and information. The cancer Bioinformatics Infrastructure Objects (caBIO) model and architecture is the primary programmatic interface to caCORE. The heart of caBIO is its domain objects, each of which represents an entity found in biomedical research. These domain objects are related to each other, and examining these relationships can bring to the surface biomedical knowledge that was previously buried in the various primary data sources. 